\title{
КЛАСТЕРИЗАЦИЯ ПРОМЫШЛЕННОСТИ КАК ИНСТРУМЕНТ ОБЕСПЕЧЕНИЯ КОНКУРЕНТНЫХ ПРЕИМУЩЕСТВ НАЦИОНАЛЬНОЙ ЭКОНОМИКИ: МЕЖДУНАРОДНЫЙ ОПЫТ И ПЕРСПЕКТИВЫ ДЛЯ РОССИИ
}

\section{INDUSTRY CLUSTERING AS A TOOL TO ENSURE THE COMPETITIVE ADVANTAGES OF THE NATIONAL ECONOMY: INTERNATIONAL EXPERIENCE AND PROSPECTS FOR RUSSIA}

Yu. Mindlin

Summary. The article discusses the theoretical and methodological foundations of the formation and development of industrial clusters, which are the newest and most effective tool for improving the competitiveness of the national economy. The international experience of formation and effective functioning of cluster formations is analysed. The advantages of combining enterprises into clusters and the impact of the latter on the development of technology transfer and innovation and investment development of the country and its regions in the context of global competition are determined. The features of the clustering development of the economy and its newest forms are investigated. The expediency of using the clustering mechanism in the Russian Federation based on the experience of highly developed countries of the world is substantiated. The analysis of cluster policy in the EU member states is carried out, its features and main trends in modern conditions are determined. The expediency of continuing the creation of new cluster formations in Russia as an important factor in ensuring innovative competitive advantages of the national economy in the context of digital development is substantiated. The current state is analysed, the problems of the development of innovation and industrial clusters are identified. The directions of improving the state policy of stimulating the creation and functioning of innovation and industrial clusters in Russia and attracting enterprises, research organizations, universities and financial structures to their network are proposed. Recommendations on the implementation of cluster strategies in all industrial sectors of the economy have been developed.

Keywords: clusters, clustering of the economy, competitive advantages, European innovation space.
$\mathbf{X}$ арактерной чертой современного мира является его быстрое изменение, трансформация и адаптивность к новым условиям функционирования и развития, что обусловлено радикальными социально-экономическими трансформациями. Реша-

\author{
Миндлин Юрий Борисович \\ К.э.н., дочент, ФГБОУ ВО «Московская \\ государственная академия ветеринарной медицины \\ и биотехнологии имени К.И. Скрябина» \\ mindliny@mail.ru
}

Аннотация. В статье рассмотрены теоретико-методологические основы становления и развития промышленных кластеров, которые являются новейшим и эффективным инструментом повышения конкурентоспособности национальной экономики. Проанализирован мировой опыт формирования и эффективного функционирования кластерных образований. Определены преимущества объединения предприятий в кластеры и влияние последних на развитие трансферта технологий и инновационно-инвестиционное развитие страны и ее регионов в условиях глобальной конкуренции. Исследованы особенности развития кластеризации экономики и ее новейших форм. Обоснована целесообразность использования механизма кластеризации в Российской Федерации на основе опыта высокоразвитых стран мира. Проведен анализ кластерной политики в странах-членах ЕС, определены ее особенности и основные тенденции В современных условиях. Обоснована целесообразность продолжения создания новых кластерных образований в России как важного фактора обеспечения инновационных конкурентных преимуществ национальной экономики в условиях цифрового развития. Проанализировано современное состояние, выявлены проблемы развития инновационно-промышленных кластеров. Предложены направления совершенствования государственной политики стимулирования создания и функционирования инновационно-промышленных кластеров в России и привлечения к их сети предприятий, научно-исследовательских организаций, университетов и финансовых структур. Разработаны рекомендации по внедрению кластерных стратегий во все промышленные сектора экономики.

Ключевые слова: кластеры, кластеризация экономики, конкурентные преимущества, европейский инновационный пространство.

ющим фактором таких существенных изменений стали стремительные и выдающиеся научно-технические достижения человечества фактически во всех ведущих сферах, в частности в сфере компьютеризации, информатизации, био- и нанотехнологий, в средствах 
коммуникации и обмена информации, связи, а также в сфере высоких технологий. Ведущим феноменом начала третьего тысячелетия стала интернационализация национальных экономик в условиях усиления их экономической и политической взаимозависимости. Все это, в свою очередь, активизировало и существенно увеличило стремительный обмен капиталами, инвестициями, товарами, услугами, информацией и идеями [6].

Прогрессивным направлением для нынешнего состояния управления процессами в административно-территориальных формированиях является ориентация на кластерное развитие, которое является фактором ускорения экономического роста. Кластеры, как показывает мировой опыт, имеют большое влияние на процессы усиления конкурентоспособности национальной экономики и быстрого развития инновационной деятельности в стране.

Необходимо ввести концепцию кластеризации, которая бы предусматривала цели, задачи и приоритетные направления развития производственных предприятий и внедряла проекты по реализации мер кластерной политики на региональном и национальном уровнях, что приведет к ускорению процессов технологического обновления экономики РФ [3].

Разработка стратегических направлений формирования кластерных структур в России обусловлена потребностью обеспечение модернизации экономики страны в сложных современных условиях. Концептуально кластеризация экономики базируется на сочетании общенациональных и региональных интересов и возможностей для укрепление сферы материального производства и на этой основе повышение жизненного уровня населения.

В современных условиях процессы глобализации кардинально влияют на экономическое развитие многих стран мира и предпринимательскую деятельность. В этих условиях возникает необходимость поиска конкурентных преимуществ на основе новых форм организации бизнеса. В мировом хозяйстве происходят значительные изменения в организации производства как на национальном и региональном, так и на международном уровнях. Они вызывают к жизни новейшие территориальные и интеграционные объединения кластеры, которые представляют собой добровольное объединение хозяйствующих субъектов, расположенных на определенной территории.

Как зарубежные, так и отечественные исследователи все больше внимания уделяют вопросам экономического развития на основе межрегиональной кластеризации, что обуславливается возможностью повышения конкурентоспособности государства и отдельных ее регионов за счет интеграции производственных и обеспечивающих (инфраструктурных) предприятий в одно целое для совместного достижения поставленных целей. Однако научно-прикладная деятельность в этом направлении на сегодня развита недостаточно.

В условиях глобализации конкурентоспособность национальных экономик зависит прежде всего от эффективности их организации и степени интегрированности в их пределах различных регионов, отраслей и производств. И сегодня именно кластеризация экономики является необходимой формой внутренней интеграции и кооперации, которая способна обеспечить не только устойчивость, но и эффект противодействия вызовам глобальной конкуренции со стороны имеющихся монопольных образований.

Кластеризация экономики получает широкое распространение в мире как основной инструмент развития конкурентоспособности, стимулирования инноваций, привлечение инвестиций, создание современных технологий. Опыт развитых стран свидетельствует, что возможности кластерного подхода используют для решения задач, направленных на подъем экономики отдельных отраслей и регионов. Кластеры привлекают гораздо больше инвестиций, чем отдельные компании. Этом, как правило, способствуют мультипликативное усиление действий предприятий, которые объединяются для достижения общей цели - повышение индивидуальной конкурентоспособности на основе использования суммарных конкурентных преимуществ. Пример разных стран мира и регионов, где расположены кластеры, вызывает заинтересованность местных, региональных и национальных органов исполнительной власти других стран, мотивируя их проводить кластерно ориентированную политику.

Как показывает современная практика, степень кластеризации экономической деятельности в мире достаточно высока. Современные кластерные теории связаны с развитием постиндустриального и информационного общества. Исследуя его природу, американский футуролог Э. Тоффлер в своей трилогии «Шок будущего» (1971 г.), «Третья волна» (1980 г.) и «Метаморфозы власти» (1990 г.) и других работах использовал термины «супериндустриальное общество» и «общество третьей волны». Особую роль в развитии постиндустриального и информационного общества он отводил кластеризации экономики. По его мнению, именно «кластерная интеграция способствовала внедрению инноваций и привела к повышению конкурентоспособности многих стран. Постиндустриальная парадигма характеризуется неиерархическим порядком или так называемым сетевым механизмом 
координации. Мировая экономика и все ее подсистемы стратифицируются в кластерно-сетевые структуры с горизонтальными связями и механизмом коллаборации (гибридная модель - гибкая и одновременно интегрированная)» [1].

Основные положения теории кластеризации были сформулированы в работах известных зарубежных ученых: А. Маршалла, П. Кругмана, М. Портера, А. Скотта, П. Фишера, Д. Якобсона и других. Они рассматривают феномен кластеризации как закономерный этап и фактор объективного развития рыночных систем.

В частности, А. Маршалл рассматривал кластеры (от англ. cluster - группа, скопления) как «сконцентрированные по географическому признаку группы взаимосвязанных между собой компаний в соответствующих отраслях, специализированных поставщиков, а также причастных к их деятельности организаций (университеты, торговые объединения, агентства стандартизации), что, конкурируя между собой, вместе проводят совместную работу» [2].

Весомый вклад в развитие современной теории кластеризации сделал американский ученый М. Портер, который считается одним из ее основателей. Он признает, что свои идеи он почерпнул из трудов А. Маршалла о «концентрации специализированных отраслей в отдельных местностях» [3]. В своих работах он рассматривал кластеры (промышленные группы) как группы близких, географически взаимосвязанных компаний и связанных с ими организаций, которые совместно действуют в определенном виде бизнеса, характеризуются общностью направлений деятельности и взаимодополняют друг друга.

Но М. Портер сосредотачивал свои исследования кластеризации экономики в основном с позиции создания конкурентных преимуществ. По его мнению, кластеры охватывают значительное количество разного рода предпринимательских структур, важных для конкурентной борьбы, а именно: поставщиков специального оснащения, новых инновационных технологий и услуг, инфраструктуры, сырья, дополнительных продуктов и тому подобное. Кроме того, «... многие кластеры включают органы власти и другие учреждения - такие, как университеты, центры стандартизации, торговые ассоциации, которые обеспечивают образование, специализированное переобучение, информацию, исследования и техническую поддержку» [4]. Итак, М. Портер считал, что главным мотивом для организации промышленных кластеров является то, что у них создаются наилучшие условия для повышения конкурентоспособности субъектов хозяйствования и экономики в целом.
Современные кластеры способны трансформировать конкуренцию в интеграционную кооперацию, не разрушая ее как здоровую движущую силу мировой экономики. Сетевая национальная экономика становится мощным двигателем социально-экономического роста и механизмом национальной безопасности перед угрозой тотального корпоративного глобализма. Кластеры защищают национальных производителей от влияния глобальных монополий, тем самым обеспечивающих реализацию собственных национальных интересов стран. Мировая практика подтверждает, что лидерство в экономическом росте сегодня получают те страны или регионы, на территории которых образовались кластеры, и именно последние определяют конкурентоспособность национальных экономик.

В то же время те страны или регионы, в пределах которых не сформировались кластеры, постепенно отходят на второй план или превращаются в аутсайдеров $[5]$.

В современных условиях кластеры имеют значительный интеграционный потенциал. Да, в частности, по мнению К. Чейна, «специфика функционирования кластеров, заключается в интеграции отраслевых и территориальных принципов организации предпринимательской деятельности, возможности более полного использования инфраструктурного потенциала страны и ее регионов, а также способности к изменению конфигурации сети: замены отдельных элементов, присоединение дополнительных подобных» [6].

В экономической литературе существуют и другие научные подходы относительно сущности кластеров (М. Энрайт, Э. Бергман и Э. Фезер) [7]: связанные с поддержкой кластерной теории внешней экономики; выделяющие инновационную среду как отдельную природу инноваций, рассматривающие кластеры с позиции кооперативной конкуренции, межфирменной конкуренции, а также как выбор пути развития не поведенческой природы.

На сегодня единого определения для понятия «кластер» среди ученых нет. Однако наиболее полно его суть, по нашему мнению, раскрывает В.А. Агафонов, который отмечает, что кластер или сетевая промышленная группа - это «группа близких, географически взаимосвязанных предприятий и организаций, с ими сотрудничают, совместно действуют в определенном виде бизнеса и характеризуются общностью направлений деятельности на производство продукции мирового уровня и взаимодополнением друг друга» [8].

Отдельные исследователи отождествляют понятие «кластер» с понятием «кластеризация». В научной лите- 
ратуре существуют определенные расхождения относительно толкование этого понятия, однако обобщение литературных источников позволяет указать на то, что кластеризация является комплексом организационно-экономических мероприятий, осуществляемых государственными, частными или общественными институтами для объединения предприятий и учреждений в кластеры, установления между ними неформальных взаимоотношений и сетевого сотрудничества [9; 10].

Концепция кластеризации сегодня является одним из новых и прогрессивных направлений как теории, так и практики изучения, организации и развития экономической деятельности, которое показало свою эффективность во многих странах мира. Эта концепция сформировалась в 80-х гг. XX в. и обобщила в себе лучшее из многих предыдущих теорий, а именно: конкурентоспособность, институциональный, инновационное, территориальное и промышленное развитие [11].

В конце XX в. экономическая власть во многих развитых странах миру значительное внимание начала уделять реализации мероприятий, которые базируются на кластерной концепции регионального развития. Ради этого в этих странах происходят кардинальные трансформационные изменения в экономической и социальной сферах, развиваются современные организационно-экономические формы сотрудничества на рыночных началах. На государственном и региональном уровнях создается соответствующая институциональная инфраструктура (агентства, институты, департаменты и т.д.), направлена на формирование и развитие региональных кластерных образований.

Распространяя идею развития кластеров, ученые предлагают сформулировать категорию кластеров как группы промышленных предприятий, которые кооперируются и поддерживают друг друга, сформировавшейся на основе территориальной концентрации основного производства, сети специализированных поставщиков и потребителей, связанных между собой технологическими цепями [8].

С точки зрения регионального развития в контексте формирования кластерных образований целесообразно, прежде все, определить его инвестиционную привлекательность. Автор предлагает при ее определении использовать методику исследования экономического потенциала региона (исторический задел-отраслевое преобладание - ресурсообеспеченность отрасли-инвестиционный климат).

Кластеризация экономики сопровождается реализацией общегосударственной политики и национальных программ социально-экономического развития, направленных на поддержку инновационного и научно-технологического развития страны, проведением децентрализации управления экономики и реформированием регуляторных и бюджетно-фискальных механизмов, разработкой общенациональных и региональных стратегий территориального развития.

Разработка и реализация национальных программ инновационного и научнотехнологического развития стран должна осуществляться, учитывая современные интеграционные процессы и на разных экономических уровнях. Для стран-участниц интеграционных образований это предусматривает разработку и реализацию единой инновационной политики и формирования общего инновационного пространства и рынка.

Научно-техническая интеграция в странах-членах ЕС на современном этапе предусматривает создание единого инновационного пространства и рынка инновационных технологий, международных сетей обмена опытом в сфере инноваций и различных программ сотрудничества в научно-технической сфере. Прежде всего, это создание широкой сети специализированных центров совершенства в странах Европы и виртуальных центров с помощью новых инструментов интерактивного общения. В ряду других приоритетов является использование инструментов и ресурсов для привлечения инвестиций в научные исследования и разработки и инновации, таких как системы косвенной помощи, рисковый капитал, новые инструменты защиты интеллектуальной собственности. Кроме того, предусмотрена возможность введения и ряда других инструментов политики улучшение трансфера научных знаний: базы данных и информационные системы; структуры и механизмы обмена информацией и опытом.

Как институциональное обеспечение развития общего инновационного пространства в ЕС были созданы такие институты, как Европейский исследовательский совет и Европейский Технологический институт, на базе которых предусмотрено сформировать европейское научно-техническое и инновационное сообщество мирового класса [12].

В Европе процесс кластеризации связан с рядом государственных мероприятий, а именно созданием в 1968 г. Генерального директората по региональной политике, в 1975 г.- Европейского фонда регионального развития, а в 1988 г.- принятия Хартии регионализма, начала деятельность Совета региональных и местных обществ [12]. Значительную финансовую и экспертную помощь со стороны ЕС, Организации «Центральная европейская инициатива», ЕБРР, других институтов получили постсоциалистические страны Центральной и Восточной Европы, что значительно 
способствовало реформированию их экономик до современных рыночных требований, повысило их конкурентные преимущества на международных рынках [11].

Кластерные объединения получили широкое развитие в ведущих экономиках мира - США, многих странах-членах ЕС и Азии, где теорию кластеров считают одним из основных инструментов повышения уровня конкурентоспособности отдельных отраслей и экономики в целом. Например, в странах-членах ЕС сейчас насчитывается более 2 тыс. кластеров, в которых работает более $40 \%$ всей европейской рабочей силы. Кластеризацией полностью охвачена промышленность Дании, Норвегии, Швеции, Финляндии. Так, в Финляндии создано и функционирует 9 кластеров, которые отличаются высокой производительностью. Располагая всего 0,5\% мировых лесных ресурсов, эта страна обеспечивает 10\% мирового экспорта продукции деревопереработки и $25 \%$ - бумаги. Кроме лесного, важнейшими для экономики Финляндии являются также информационный и телекоммуникационный кластеры, что обеспечивают совокупно основной объем экспорта и формируют значительную часть ВВП страны. В результате проведения экономической политики, базирующейся на кластеризации, Финляндия в течение 2000-х гг. занимает ведущие места в мировых рейтингах конкурентоспособности [12].

Интересный опыт формирования кластерных образований имеет Дания. Проведенная в этой стране за несколько лет работа вывела ее в мировые лидеры кластеризации экономики, в которой сегодня функционируют 29 ведущих кластеров, в Нидерландах также высокий уровень кластеризации экономики, которая разбита на 20 «мегакластеров» [12].

В Германии достаточно эффективно функционируют кластеры в промышленности, прежде всего в машиностроении, химии и биотехнологиях. Последние годы именно благодаря кластеризации экономики Германия стала на международном уровне признанным научным и экономическим лидером в сфере биотехнологий. Сегодня в этой сфере Германия значительно опережает многие другие развитые страны, а оборот этой отрасли промышленности превышает 3 млрд. евро. В сфере биотехнологий научные исследования обеспечивают более 30 тыс. ученых. Расходы на научные исследования и разработки в этой области достигают более 1 млрд. евро [9].

В Италии получили развитие промышленные округа (кластеры), в которых задействованы около $30 \%$ рабочей силы от общего уровня занятости. Индустриальные кластеры характеризуются высокой концентрацией небольших фирм традиционной обрабатывающей про- мышленности. Италия - страна, где преобладают небольшие компании, и на сегодня из 4 млн. фирм лишь $2 \%$ - это крупные компании. Всего в Италии функционирует 200 индустриальных округов, объединяющих 60 тыс. предприятий и производится более 1/3 объемов экспортной продукции [7].

Это традиционные способы государственного регулирование экономики, которые могут быть успешно реализованы в России [5].

Распространенность кластерных стратегий очень неравномерна между странами; различаются и практики их осуществления. Кластерная модель в европейских странах значительно отличается от американской и азиатской большим количеством кластеров (сегодня, по разным экспертным оценкам, насчитывается более 2000 кластеров) и прямым влиянием на их деятельность со стороны государства и правительственных учреждений, а также значительной финансовой поддержкой кластерных образований (кластерные программы, инициативы, общие стратегии инновационного развития, финансирования сектора НИОКР) [9].

Кластерная политика стран-членов ЕС сосредоточена в основном на формировании и поддержке эффективного функционирования успешных кластеров. Она соединила в себе важные структурные компоненты региональной, научнотехнической, инновационной и промышленной политик благодаря достижению единой цели: объединить всех участников-представителей предпринимательских структур, науки, власти для повышения конкурентоспособности стран-членов ЕС и их регионов путем реализации инновационно-инвестиционной модели развития, применяя которую формируют инновационные конкурентные преимущества страны в условиях глобальной конкуренции. Важным условием эффективности кластерной политики есть результативное взаимодействие и сотрудничество правительственных организаций на всех от регионального и местного - до наднационального. В странах-членах ЕС большинство конкурентоспособных кластеров было образовано в результате сочетание усилий правительств стран, региональных властей и представителей менеджмента кластеров и предпринимательских структур.

Сравнительный анализ основных составляющих кластерных программ европейских стран показывает наличие устойчивых тенденций по формированию механизмов и инструментов их реализации в соответствии с определенными приоритетами регионального развития и национальных экономик в целом, которые могут включать: привлечение новых субъектов к участию в деятельности кластерных образований; разви- 
тие сферы предоставление коллективных услуг и поддержки (проведение обучающих тренингов; развитие информационно-коммуникационной инфраструктуры; коммерциализация научно-технических разработок и технологий, международный трансфер технологий и его информационное обеспечение); создание благоприятных условий для бизнесреды и улучшения инвестиционного климата; стимулирование совместных частно-государственных НИОКР; масштабную поддержку кластерных инициатив как с стороны государства, так и предпринимательскими структурами [12].

Сегодня кластерная политика в странах Европы направлена на формирование общей европейской бизнес-среды и реализуется на трех различных уровнях: первый - на мегауровне через общеевропейские программы поддержки, которые финансируются Европейской комиссией и структурными фондами ЕС; второйна макроуровне посредством реализации кластерных программ в отдельных европейских странах на национальном и региональном уровнях; третий - предусматривает на микроуровне поддержку бизнесом кластеров с помощью собственных финансовых ресурсов и инициатив. Однако, несмотря на актуальность вопроса об утверждении и реализации единой кластерной политики для стран-членов ЕС, по нашему мнению, такова единая стратегия может оказаться недостаточно эффективной, учитывая наличие значительных диспропорций в уровнях и условиях экономического развития стран-членов ЕС, которые особенно обострились во время последней мировой финансово-экономической кризисы, а также исторические и культурные особенности стран и регионов.

В странах-членах ЕС с 2008 г. начался новый этап В реализации кластерной политики, который характеризуется обострением проблем, связанных с усилением глобальной конкуренции и новым европейским курсом - поддержкой и созданием мощных кластеров мирового уровня в соответствии с новой стратегией ЕС «Европа 2020». По результатам экспертных исследований Ассоциации «Европа ІнтерКластер», кластеры мирового уровня представляют кластерные образования, конкурентоспособны на мировом рынке, с мощной инновационной экономической системой, которые привлекают масштабные инвестиции и влияют на международные интеграционные процессы в экономической сфере [11].

Опыт многих стран мира доказывает, что развитие инновационно-технологических кластеров положительно влияет на экономическую и социальную ситуацию, поддерживает процесс модернизации промышленности. В инновационно-промышленных кластерах применяются современные технологии и инновации в производственных процессах, производят высококачественные товары, улучшается исследовательский потенциал страны. Деятельность инновационно-промышленных кластеров создает благоприятные условия для развития малого и среднего бизнеса, сотрудничества с иностранными экономическими субъектами и поэтому положительно влияет на конкурентоспособность, производительность труда и повышение уровня занятости населения, решения проблем трудоустройства и тому подобное [13].

В современных условиях расширения процессов глобализации и регионализации международного сотрудничества значительно возрастает роль трансграничного сотрудничества регионов РФ, прежде всего в инновационно-инвестиционной сфере, открывающей новые возможности для активизации предпринимательства на периферийных территориях и повышение их конкурентоспособности. Трансграничное сотрудничество как форма межгосударственной интеграции и интенсификации связей приграничных регионов занимает важное место в системе международных экономических отношений. Например, в Австрии действуют трансграничные кластеры с Германией, Италией, Швейцарией, Венгрией, активизировались связи с Францией и Великобританией. Разработана политика стимулирования развития связей между исследовательскими институтами и промышленным сектором, снижены регуляторные барьеры в инновационных программах, формируются центры конкурентоспособности. Особое распространение таково сотрудничество приобрело в виде еврорегионов, заключающегося в объединении приграничных территорий для их дальнейшего развития, прежде всего экономической интеграции и эффективного решения общих проблем [12].

Важной основой реализации евроинтеграционной экономической политики РФ должна быть разработка общегосударственных и регионально ориентированных стратегических программ развития, направленных на адаптацию отечественной промышленности к стандартам ЕС и обеспечения инновационных конкурентных преимуществ на международных рынках. Развитие инновационных инициатив субъектов хозяйствование в условиях кластерной организации производства является важным направлением ускорения интеграционных процессов в Европейский экономический и инновационное пространство. Однако при их реализации возникает ряд проблем как институционального, так и экономико-правового характера. Поэтому поиск путей преодоление препятствий формирования и развития кластерных образований является одним из главных стратегических приоритетов инновационного развития предпринимательских структур в реальном секторе экономики. 
На сегодня в России уже сформирована почва для развития кластеров. Однако их развитие связано с наличием значительных препятствий институционального и экономико-правового характера, для преодоления которых необходимо: провести системные реформы, которые обеспечат адаптацию отечественного хозяйственного законодательства к европейским стандартам; создать механизмы межгосударственной кластерной кооперации с экономически развитыми странами мира, в частности со странами-членами ЕС для оптимизации процессов экономической евроинтеграции.

Подводя итоги, можем констатировать тот факт, что кластерные образования в современных условиях хозяйствования акциональной экономики является одним из перспективных направлений организации инновационных процессов, что позволяет конкурировать на рынке не одному субъекту хозяйствования, а целым комплексам, А это в свою очередь позволяет группе предприятий уменьшать определенные статьи расходов. Кроме того, объединение предприятий в кластеры формирует специфическое экономическое пространство с целью расширения сферы свободной торговли, свободного перемещение капитала и человеческих ресурсов, а следовательно, выполняет функции структурообразующих элементов глобальной цифровой экономики. Следует отметить еще и тот факт, что практика деятельности существующих отечественных и зарубежных кластеров доказывает тезис относительно кластера как эффективной формы ведения бизнеса с целью конкурентной борьбы и инновационного развития субъектов хозяйствования.

\section{ЛИТЕРАТУРА}

1. Тоффлер э. Третья волна. М.: АСТ, 1999. 261 с.

2. Маршалл А. Принципы экономической науки: в 3-х т. М.: Наука, 1993. Т. 1.594 с.

3. Портер М. Международная конкуренция: конкурентные преимущества стран. М.: Международные отношения, 1993. 896 с.

4. Портер М. Конкуренция / пер. с англ. М.: Вильямс, 2006. 608 с.

5. Шаститко А.Е. Кластеры как форма пространственной организации хозяйственной деятельности: теория вопроса и эмпирические наблюдения // Балтийский регион. 2009. № 2. С. 9-31.

6. Chen C.L. Value creation by SMEs participating in global value chains under industry 4.0 trend: Case study of textile industry in Taiwan // Journal of Global Information Technology Management. 2019. vol. 22, №.2, pp. 120-145. https://doi.org/10.1080/1097198X.2019.1603512.

7. Bergman E.M., Feser E.J. Industrial and Regional Clusters: Concepts and Comparative Applications. Web Book in Regional Science. Morganton, WV: Regional Research Institute, West Virginia University, 1999. 342 p.

8. Агафонов В.А. Региональные инновационные кластеры // Региональная экономика и управление: электронный научный журнал. 2015. № 3(43). C. $2-16$.

9. Ц Церцеил Ю.С., Коокуева В.В. Роль инновационных промышленных кластеров в развитии региональной экономики // Российское предпринимательств0. 2016. Т. 17, № 20. С. 2779-2796.

10. Федоров С.И. Кластерная политика и инновационная активность промышленных предприятий // Вестник Московского университета. Серия 6. Экономика. 2021. № 4. С. 161-185. https://doi.org/10.38050/01300105202148.

11. Кудрявцева Т.Ю., Жабин Н.П. Формирование алгоритма идентификации кластеров в экономике региона // Научно-технические ведомости Санкт-Петербургского государственного политехнического университета. Экономические науки. 2014. № 3(197). С. 124-131.

12. European Cluster Observatory: Website. 2018. URL: http://www.clusterobservatory.eu

13. Валитова Л.А., Шарко Е.Р., Шерешева М.Ю. Выделение промышленных кластеров на основе анализа бизнес-связей: пример текстильной отрасли // Управленец. 2021. Т. 12, № 4. С. 59-74. https://doi.org/10.29141/2218-5003-2021-12-4-5. 